\title{
QTc Prolongation in COVID-19 Patients Using Chloroquine
}

\author{
Matthijs L. Becker ${ }^{1,2}$. Dominic Snijders ${ }^{3} \cdot$ Claudia W. van Gemeren $^{4} \cdot$ Hylke Jan Kingma $^{1,2}$. \\ Steven F. L. van Lelyveld ${ }^{5}$. Thijs J. Giezen ${ }^{1,2}$
}

Received: 27 May 2020 / Accepted: 24 November 2020 / Published online: 2 January 2021

(C) The Author(s), under exclusive licence to Springer Science+Business Media, LLC part of Springer Nature 2021

\begin{abstract}
Chloroquine is used in the treatment of patients with COVID-19 infection, although there is no substantial evidence for a beneficial effect. Chloroquine is known to prolong the QRS and QTc interval on the ECG. To assess the effect of chloroquine on QRS and QTc intervals in COVID-19 patients, we included all inpatients treated with chloroquine for COVID-19 in the Spaarne Gasthuis (Haarlem/Hoofddorp, the Netherlands) and had an ECG performed both in the $72 \mathrm{~h}$ before and during or at least $48 \mathrm{~h}$ after treatment. We analyzed the (change in) QRS and QTc interval using the one-sample $t$-test. Of the 106 patients treated with chloroquine, 70 met the inclusion criteria. The average change in QRS interval was $6.0 \mathrm{~ms}(95 \%$ CI 3.3-8.7) and the average change in QTc interval was $32.6 \mathrm{~ms}$ (95\% CI 24.9-40.2) corrected with the Bazett's formula and $38.1 \mathrm{~ms}$ (95\% CI 30.4-45.9) corrected with the Fridericia's formula. In 19 of the 70 patients (27\%), the QTc interval was above $500 \mathrm{~ms}$ after start of chloroquine treatment or the change in QTc interval was more than $60 \mathrm{~ms}$. A heart rate above $90 \mathrm{bpm}$, renal dysfunction, and a QTc interval below $450 \mathrm{~ms}$ were risk factors for QTc interval prolongation. Chloroquine prolongs the QTc interval in a substantial number of patients, potentially causing rhythm disturbances. Since there is no substantial evidence for a beneficial effect of chloroquine, these results discourage its use in COVID-19 patients.
\end{abstract}

Keywords COVID-19 $\cdot$ Chloroquine $\cdot$ Long-QT syndrome/chemically induced $\cdot$ Electrocardiography $\cdot$ Drug-related side effects and adverse reactions

Handling Editor: Filomain Nguemo.

Electronic supplementary material The online version of this article (https://doi.org/10.1007/s12012-020-09621-2) contains supplementary material, which is available to authorized users.

Matthijs L. Becker

mbecker@sahz.nl

Dominic Snijders

dsnijders@spaarnegasthuis.nl

Claudia W. van Gemeren

c.van.gemeren@spaarnegasthuis.nl

Hylke Jan Kingma

hkingma@sahz.nl

Steven F. L. van Lelyveld

s.van.lelyveld@spaarnegasthuis.nl

Thijs J. Giezen

tgiezen@sahz.nl

\section{Introduction}

Chloroquine is used for the treatment of patients with COVID-19 infection, caused by the severe acute respiratory syndrome coronavirus 2 (SARS-CoV-2). There is debate about the use of chloroquine for this indication. In vitro data have shown antiviral activity of chloroquine on SARSCoV-2 [1, 2]. However, there is no substantial evidence

1 Pharmacy Foundation of Haarlem Hospitals, Boerhaavelaan 24, 2035 RC Haarlem, The Netherlands

2 Department of Hospital Pharmacy, Spaarne Gasthuis, Spaarnepoort 1, 2134 TM Hoofddorp, The Netherlands

3 Department of Pulmonary Disease, Spaarne Gasthuis, Spaarnepoort 1, 2134 TM Hoofddorp, The Netherlands

4 Intensive Care Unit, Spaarne Gasthuis, Spaarnepoort 1, 2134 TM Hoofddorp, The Netherlands

5 Department of Internal Medicine, Spaarne Gasthuis, Spaarnepoort 1, 2134 TM Hoofddorp, The Netherlands 
for clinical efficacy in the treatment of COVID-19 patients [3-7]. Moreover, data has been published regarding potential toxicity associated with chloroquine treatment $[8,9]$. The Dutch guidelines, applicable in March and April 2020, stated that the use of chloroquine could be considered [10, 11], while other guidelines at that time mentioned that there is insufficient evidence to issue a recommendation [12]. In the Dutch guidelines, the recommended dose regimen was a loading dose of $600 \mathrm{mg}$ chloroquine base, followed by $300 \mathrm{mg}$ chloroquine base twice daily for a total period of 5 days $[10,11]$. The dose of $300 \mathrm{mg}$ chloroquine base is equivalent to $500 \mathrm{mg}$ chloroquine phosphate.

Chloroquine has been marketed since 1934 and is used in the treatment and prevention of malaria, and in the treatment of chronic inflammatory diseases, including systemic lupus erythematosus and rheumatoid arthritis. One of the major concerns with the use of chloroquine is its cardiotoxicity, related to QRS widening and QTc interval prolongation $[13,14]$. Prolongation of the QTc interval is associated with an increased risk of Torsades de Pointes (TdP). The risk of drug-induced TdP is especially increased in patients with risk factors, such as hypokalemia, hypocalcemia, hypomagnesemia, myocardial infarction, and congestive heart failure $[15,16]$. In these patients, the use of QTc prolonging drugs should be avoided if possible or QTc prolongation should be monitored.

Chloroquine is a racemic mixture consisting of equal quantities of S-chloroquine and D-chloroquine enantiomers. It is suggested that the S-chloroquine enantiomer is more cardiotoxic than the D-chloroquine enantiomer [17]. In an unpublished paper, the S-chloroquine enantiomer had more antiviral activity against SARS-CoV-2 [18]. Local guidelines recommended evaluation of QTc time before start and ECG monitoring during treatment in patients using other QT prolonging drugs and with a history of ventricular arrhythmias, myocardial infarction, or congestive heart failure and in patients with congenital long-QT syndrome.

Since treatment with chloroquine in COVID-19 patients is relatively short, the risk of arrhythmic toxicity is considered to be low $[14,19]$. However, the SARS-CoV-2 virus potentially has cardiac and arrhythmogenic effects, possibly resulting in more cardiotoxicity [20].

To assess the cardiotoxic effects of chloroquine in COVID-19 patients, we retrospectively assessed the effect of chloroquine on the QRS and QTc interval.

\section{Methods}

\section{Setting}

This study was performed in the Spaarne Gasthuis (Haarlem/ Hoofddorp, the Netherlands), a general teaching hospital.

\section{Study Cohort}

We performed an observational cohort study. The inclusion criteria was admission between 1 March and 19 April 2020 with a COVID-19 infection, and chloroquine treatment started during this admission with an ECG performed both in the $72 \mathrm{~h}$ before start of chloroquine treatment and during or within $48 \mathrm{~h}$ after the end of chloroquine treatment. The exclusion criteria were a baseline QTc above $500 \mathrm{~ms}$, a known left or right bundle branch block, and having a pacemaker implanted. According to the local protocol adapted from the Dutch national guidelines, chloroquine treatment was considered in admitted patients in need for supplemental oxygen without pre-existing contraindications. We selected all ECGs that were performed in routine clinical practice.

\section{Data Collection}

Data were extracted from the hospital information system EPIC (Madison, WI, USA), using SAP Crystal Reports (Walldorf, Germany). All ECGs were standard 12-lead resting ECGs $(25 \mathrm{~mm} / \mathrm{s}$ paper speed, $10 \mathrm{~mm} / \mathrm{mV}$ amplitude, and $40 \mathrm{~Hz}$ sampling rate). ECGs were recorded using GE MAC $5500 \mathrm{HD}$ with automated analysis by the Marquette 12SL ECG Analysis Program (GE Healthcare, Chicago, IL). ECG data were stored and presented in the MUSE Cardiology Information System (GE Healthcare, Chicago, IL). The heart rate (RR), QT, and QRS interval were analyzed by the MUSE system and recorded in the hospital information system EPIC. For each ECG, we collected the cumulative dose of chloroquine administered, the last measured serum potassium level, and whether other QT prolonging drugs or furosemide were administered in the $24 \mathrm{~h}$ before the ECG. We also collected the last serum creatinine and calcium level before the start of chloroquine therapy. Renal function was analyzed as the estimated glomerular filtration rate (eGFR) calculated with the CKD-EPI formula. As QT prolonging drugs, we used the list of drugs with a known risk of TdP according to the CredibleMeds list [21]. The patient's medical files were searched for cardiovascular morbidities and the reason for discontinuation if patients stopped chloroquine treatment prematurely.

\section{Outcome and Study Variables}

We used both the Bazett's formula $\left(\mathrm{QTc}=\mathrm{QT} / \mathrm{RR}^{1 / 2}\right)$ and Fridericia's formula $\left(\mathrm{QTc}=\mathrm{QT} / \mathrm{RR}^{1 / 3}\right)$ to correct the $\mathrm{QT}$ interval for the heart rate $[22,23]$. We analyzed the change in QRS and QTc interval between the last ECG performed before start of chloroquine treatment and the first ECG performed during chloroquine treatment. We also analyzed the 
number of patients with a change in QTc of more than $60 \mathrm{~ms}$ or a QTc interval of more than $500 \mathrm{~ms}$ at the first ECG after start, and the change in QTc interval between the first and second ECG performed during chloroquine treatment. We visually present the association between the cumulative chloroquine dose and the change in QTc interval with the last ECG performed before the start of chloroquine treatment. In this presentation, we include multiple ECGs per patient, if more than one ECG was recorded during treatment. If more than one ECG was recorded in a dosing interval, only the first ECG was selected.

In a subanalysis, we excluded patients with (a history of) cardiovascular disease, with hypokalemia $(<3.5 \mathrm{mmol} / \mathrm{l})$, patients who used furosemide, and patients who used QT prolonging drugs with a known risk of TdP according to the CredibleMeds list at the time of one of the two ECGs [15, 21]. Ciprofloxacin and haloperidol in a daily dose of $2 \mathrm{mg}$ or less were not regarded as QT prolonging drugs, because their effect on the QT interval is negligible [24, 25]. Age, gender, heart rate, QRS interval, QTc interval, eGFR at baseline, and ICU admission during treatment were analyzed as potential risk factors.

\section{Statistical Analysis}

We used the one-sample $t$-test to analyze the changes in QTc and QRS interval. Univariate linear regression analysis was used to analyze differences between risk factors. Risk factors significantly associated with the change in QTc interval were subsequently analyzed using multivariate linear regression. A $p$-value below 0.05 was regarded as statistically significant. Statistical analyses were performed using IBM SPSS Statistics for Windows software (IBM Corp., Version 24.0. Armonk, NY).

\section{Results}

During the study period, 188 patients were admitted with COVID-19 of whom 106 patients started with chloroquine treatment during admission. In 73 of the 106 patients, an ECG was performed both in the $72 \mathrm{~h}$ before start and during or at least $48 \mathrm{~h}$ after chloroquine treatment. Two patients were excluded with a baseline QTc above $500 \mathrm{~ms}$ and one patient was excluded due to pacemaker implantation (Table 1). All patients received the dose regimen recommended in the Dutch guidelines. The average time from the last ECG before start to the first ECG after start of chloroquine treatment was $41.5 \mathrm{~h}$ (SD 23.0). The cumulative chloroquine dose at the time of the first ECG after start was 600 to $1200 \mathrm{mg}$ for 56 of the 70 patients (80\%). On average, there was a $6.0 \mathrm{~ms}(95 \%$ CI $3.3-8.7)$ increase in the QRS interval, a $32.6 \mathrm{~ms}$ (95\% CI 24.9-40.2) increase
Table 1 Baseline characteristics $(n=70)$

\begin{tabular}{lll}
\hline Male & $79 \%$ & \\
Age (mean, SD) & $64.5 \mathrm{year}$ & 10.3 \\
Time ECG_-start chloroquine (mean, SD) & $14.7 \mathrm{~h}$ & 16.4 \\
RR (mean, SD) & $88.2 \mathrm{bpm}$ & 14.7 \\
QRS (mean, SD) & $92.9 \mathrm{~ms}$ & 20.1 \\
QTc (Bazett) (mean, SD) & $427.7 \mathrm{~ms}$ & 28.4 \\
QTc (Fridericia) (mean, SD) & $402.3 \mathrm{~ms}$ & 31.0 \\
Atrial fibrillation or Atrial flutter & $12.9 \%$ & \\
Coronary artery disease & $11.4 \%$ & \\
Other cardiovascular diseases & $7.1 \%$ & \\
Potassium level<3.0 mmol/l & $0 \%$ & \\
3.0-3.4 mmol/1 & $14.3 \%$ & \\
eGFR $<30 \mathrm{ml} /$ min $/ 1.73 \mathrm{~m}{ }^{2}$ & $1.4 \%$ & \\
$30-49 \mathrm{ml} / \mathrm{min} / 1.73 \mathrm{~m}^{2}$ & $8.6 \%$ & \\
Calcium level $(n=2)<2.15 \mathrm{mmol} / 1$ & $0 \%$ & \\
Use of QT prolonging drugs & $4.3 \%{ }^{\dagger}$ & \\
Use of furosemide & $2.9 \%$ & \\
\hline
\end{tabular}

†2 patients used ciprofloxacin, while 1 patient used haloperidol $0.5 \mathrm{mg}$

in QTc interval corrected with the Bazett's formula, and a $38.1 \mathrm{~ms}$ (95\% CI 30.4-45.9) increase in QTc interval corrected with the Fridericia's formula (Table 2, Fig. 1).

If we corrected the QTc interval with the Bazett's formula, in 19 of the 70 patients (27\%), the QTc was above $500 \mathrm{~ms}$ or the QTc increased with more than $60 \mathrm{~ms}$. In 6 of the 19 patients (32\%), risk factors (cardiovascular disease, hypokalemia, use of furosemide or use of QT prolonging drugs other than ciprofloxacin and low dose haloperidol) were present, versus in 12 of 51 patients (24\%) with no QTc above $500 \mathrm{~ms}$ or QTc increase with more than $60 \mathrm{~ms}$. The difference was not statistically significant $(p=0.49)$. The change in QTc interval minus the change in QRS interval, as a measure for the repolarization period, was $26.6 \mathrm{~ms}$ (95\% CI 19.1-34.0). In 52 of the 70 patients, no risk factors were present. In these patients, the QTc prolongation was $33.6 \mathrm{~ms}$ (95\% CI 24.8-42.5). In the 61 patients with no atrial fibrillation or atrial flutter, the QTc prolongation was $32.8 \mathrm{~ms}$ (95\% CI 24.5-41.2). Risk factors for QTc prolongation were a heart rate at or above $90 \mathrm{bpm}$ before the start of chloroquine and an eGFR below $50 \mathrm{ml} / \mathrm{min} / 1.73 \mathrm{~m}^{2}$, while a QTc interval above $450 \mathrm{~ms}$ resulted in a lower QTc prolongation (Table 3). These associations remained significant in the multivariate linear regression analysis.

Seventeen patients $(24 \%)$ had a QTc interval above $500 \mathrm{~ms}$ on an ECG during or within $48 \mathrm{~h}$ after chloroquine treatment. Eight patients stopped chloroquine treatment due to a prolonged QTc interval, two patients due to bradycar$\mathrm{dia}$, and one patient stopped due to frequent extrasystoles 
Table 2 Results from the ECG data $(n=70)$

\begin{tabular}{|c|c|c|c|}
\hline & Mean & $95 \% \mathrm{CI}$ & $p$-value \\
\hline$\Delta \mathrm{RR}$ & -8.5 & -11.9 to -5.1 & $<0.001$ \\
\hline$\Delta \mathrm{QRS}$ & 6.0 & $3.3-8.7$ & $<0.001$ \\
\hline$\Delta$ QTc (Bazett) & 32.6 & $24.9-40.2$ & $<0.001$ \\
\hline$\Delta$ QTc (Bazett) in patients with no risk factors $(n=52)$ & 33.6 & $24.8-42.5$ & $<0.001$ \\
\hline$\Delta$ QTc (Bazett) in patients with no atrial fibrillation/atrial flutter $(n=61)$ & 32.8 & $24.5-41.2$ & $<0.001$ \\
\hline$\Delta$ QTc first to second ECG during treatment (Bazett) & 18.4 & -4.2 to 41.1 & 0.11 \\
\hline$\Delta$ QTc (Bazett)— $-\Delta$ QRS & 26.6 & $19.1-34.0$ & $<0.001$ \\
\hline \multirow[t]{2}{*}{$\Delta$ QTc (Fridericia) } & 38.1 & $30.4-45.9$ & $<0.001$ \\
\hline & $N$ & & $\%$ \\
\hline QTc after start $>500 \mathrm{~ms}$ or $\Delta \mathrm{QTc}>60 \mathrm{~ms}$ (Bazett) & $19 / 70$ & & $27 \%$ \\
\hline QTc $>500 \mathrm{~ms}$ during or within $48 \mathrm{~h}$ after treatment (Bazett) & $17 / 70$ & & $24 \%$ \\
\hline
\end{tabular}

and ventricular tachycardia. In Fig. 2, the change in QTc interval compared with the QTc interval before start of chloroquine is given per cumulative dose of chloroquine. In the 24 patients with two or more ECGs performed during treatment, there was a non-significant increase in the QTc interval of $18.4 \mathrm{~ms}(95 \% \mathrm{CI}-4.2$ to 41.1$)$ from the first to the second ECG after the start of treatment with chloroquine. The average time between these ECGs was $30.2 \mathrm{~h}$ (SD 13.5).

If we corrected the QTc interval with the Fridericia's formula, the results did not differ substantially (Table A.1, Figure A.1).

\section{Discussion}

In this observational cohort study of COVID-19 patients treated with chloroquine, of whom nearly $80 \%$ was male, we found that chloroquine use resulted in a $33 \mathrm{~ms}$ increase of the QTc interval and a $6 \mathrm{~ms}$ increase in QRS interval. Around a quarter of the patients had an increase in QTc interval of more than $60 \mathrm{~ms}$, or a QTc interval after start of more than $500 \mathrm{~ms}$, which is generally accepted as a risk factor for arrhythmias such as Torsade de Pointes [26]. This increase in QTc interval is substantially more than seen with other QT prolonging drugs. In a previous study from our hospital, the average increase in QTc interval for QTc prolonging drugs with a known risk of TdP according to the CredibleMeds list was $11 \mathrm{~ms}[15,21]$. For comparison, the average increase in QTc interval in patients with a hypokalemia at or below $3.0 \mathrm{mmol} / \mathrm{l}$ in this study was $24 \mathrm{~ms}$ [15]. In our hospital, we, therefore, decided on 22 April 2020 to stop treating COVID-19 patients with chloroquine because our analysis and other studies showed that chloroquine does not improve patient outcomes and increased the risk of cardiovascular side effects, among others.
Patients with an eGFR below $50 \mathrm{ml} / \mathrm{min} / 1.73 \mathrm{~m}^{2}$ had a greater increase in QTc interval. Renal dysfunction itself is a risk factor for QTc interval prolongation, but plasma levels of chloroquine will be higher since $38 \%$ of chloroquine is excreted unchanged with the urine [14, 15]. Another risk factor was a heart rate above $90 \mathrm{bpm}$. Interestingly, patients with a baseline QTc interval above $450 \mathrm{~ms}$ had a smaller increase in QTc interval after start of chloroquine treatment. Similar results have been seen for haloperidol treatment [27]. An explanation might be that the guidelines recommend not to initiate chloroquine treatment in patients at high risk for QTc interval prolongation. Physicians may have decided to start chloroquine treatment in patients with a baseline QTc above $450 \mathrm{~ms}$ if no other risk factors for QTc interval prolongation were present. Therefore, the overall risk for QTc interval prolongation may be lower than in patients with a baseline QTc below $450 \mathrm{~ms}$. We found a $5 \mathrm{~ms}$ increase in QRS duration, which is not clinically relevant and is negligible relative to the normal variation in QRS interval [28].

Chloroquine is known to block inward sodium current $\left(\mathrm{I}_{\mathrm{Na}}\right)$, the L-type calcium current, and two potassium currents $\left(\mathrm{I}_{\mathrm{K} 1}\right.$ and $\mathrm{I}_{\mathrm{Kr}}$; the hERG channel) in the cardiomyocyte [13]. Inhibition of the inward sodium current and calcium current result in widening of the QRS complex, while inhibition of the potassium currents result in QTc prolongation. In a study administering chloroquine as an intravenous bolus injection, a widening of the QRS interval was seen, but there was no change in the QTc interval [29]. In two previous studies in healthy volunteers, prolongation of the QTc interval of $13.7 \mathrm{~ms}$ after 3 days of chloroquine base use (600 mg day 1, $600 \mathrm{mg}$ day 2, $300 \mathrm{mg}$ day 3) and prolongation of the QT interval of $15 \mathrm{~ms}$ after a single dose of $600 \mathrm{mg}$ were found $[30,31]$. The QT prolonging effect of chloroquine seen in healthy volunteers is much less than the QT prolonging effect seen in COVID-19 patients. COVID19 patients with pre-existing cardiovascular disease have a 


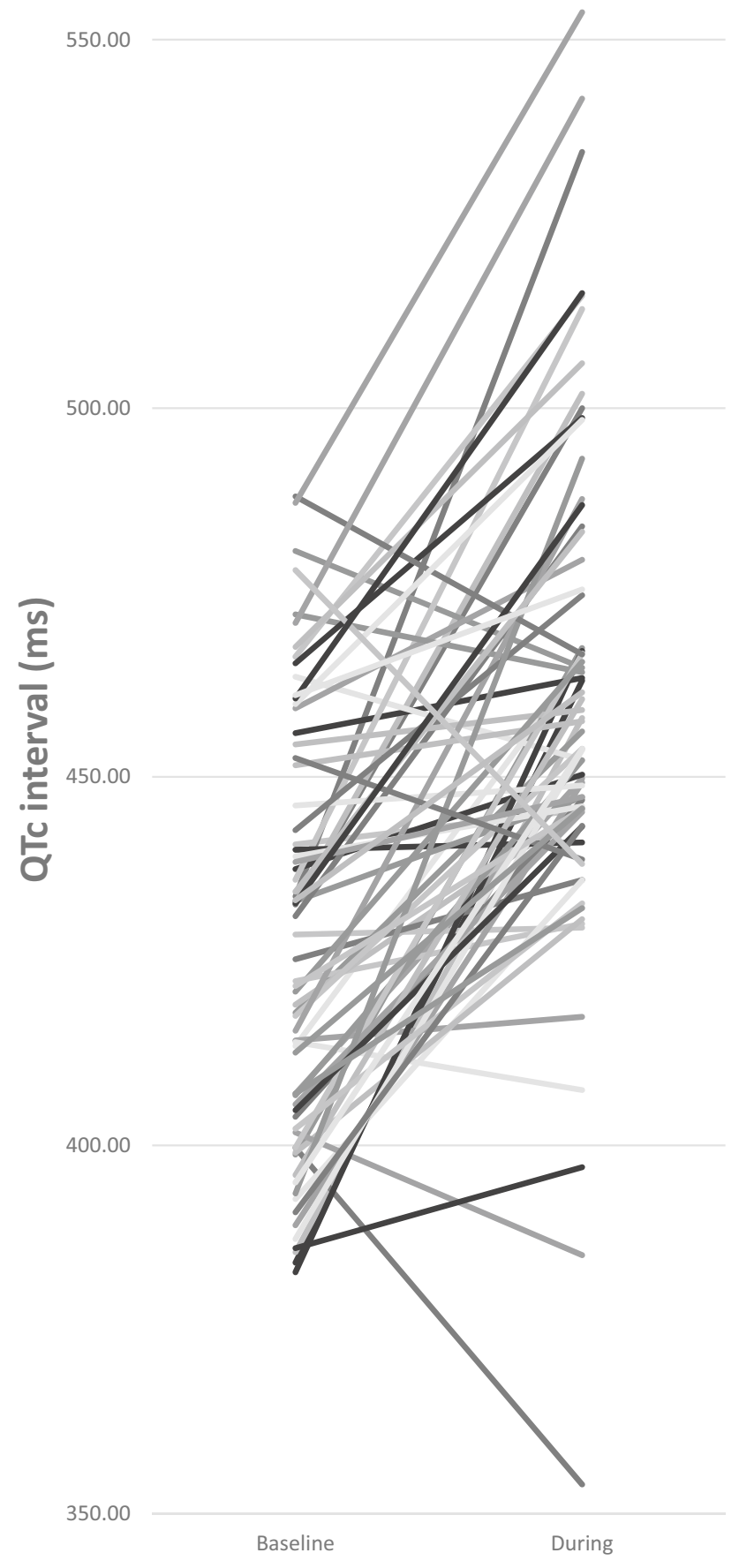

Fig. 1 Change in QTc interval corrected with the Bazett's formula. Each line represents the change in QTc interval from the last ECG before treatment to the first ECG during treatment per individual patient

worse prognosis, indicating that COVID-19 potentially has pro-arrhythmic effects [20]. This may explain the larger QT prolonging effect seen in COVID-19 patients. In a randomized clinical trial comparing chloroquine base, with $600 \mathrm{mg}$ twice daily for 10 days, $450 \mathrm{mg}$ twice daily on day 0 , and 450 once daily on day 1 to 4 in COVID-19 patients,
$19 \%$ of patients had a QTc adjusted with the Fridericia's formula above $500 \mathrm{~ms}$ in the first group and $11 \%$ of patients in the second group [8]. This trial was terminated and the authors recommend not to use the higher chloroquine dosage. In these studies no information was available on QRS interval widening. In our study, $24 \%$ of patients treated with chloroquine had a QTc interval above $500 \mathrm{~ms}$, suggesting that a dosage of $600 \mathrm{mg}$ and $300 \mathrm{mg}$ twice daily for 5 days shouldn't be recommended either.

Our results are in line with two previous studies that assessed the effect of chloroquine on the QTc interval in COVID-19 patients. In these observational studies, the same dose of chloroquine was used as in our study. Van den Broek et al. found an average increase of $35 \mathrm{~ms}$ after start of chloroquine treatment, while Sinkeler et al. found an average increase of $20 \mathrm{~ms}[32,33]$.

Three observational studies assessed the effect of hydoxychloroquine monotherapy on the QTc interval in COVID-19 patients. In the study by Mercuro et al., the average increase was $5.5 \mathrm{~ms}$, and in the study by Saleh et al., also including patients treated with chloroquine, the average increase was $14.4 \mathrm{~ms}$, while Sridhar et al. did not find an increase in QTc interval (- $2 \mathrm{~ms}$ ) [34-36]. These results may suggest that the QT prolonging effect of hydroxychloroquine is less compared to the QT prolonging effect of chloroquine. In patients using hydroxychloroquine and azithromycin, the QTc prolonging effect was larger than in patients using hydroxychloroquine monotherapy. In the study of Mercuro et al., the average change in QTc interval was $23 \mathrm{~ms}$ for the combination versus $5.5 \mathrm{~ms}$ for hydroxychloroquine monotherapy [34]. In the study by Saleh et al., the changes in QTc interval were 30.4 and 14.4, respectively [35].

Other therapeutic options for COVID-19 with no apparent cardiovascular toxicity have emerged. Three randomized clinical trials have been published that assessed remdesivir in the treatment of COVID-19. In the study by Beigel et al., 10 day treatment with remdesivir was superior to placebo, while in the study by Wang et al. no statistically significant differences were seen $[37,38]$. In the study by Spinner et al., patients receiving a 5 day treatment of remdesivir had improved clinical status at day 11 compared to patients treated with placebo, while no differences were seen between patients receiving a 10 day treatment of remdesivir compared to patients treated with placebo [39]. In the study by Beigel et al., adverse events classified as cardiac disorders were reported in $2.8 \%$ of patients using remdesivir versus $1.6 \%$ of patients using placebo [37]. In the study by Wang et al., serious cardiac adverse events (cardiac arrest, acute coronary symptoms or tachycardia) were reported in $0.6 \%$ of patients using remdesivir versus in $2.6 \%$ of patients using placebo [38]. Spinner et al. did not report on cardiac adverse events [39]. In the patients receiving oxygen or invasive mechanical ventilation, the incidence of death was lower in 
Table 3 Risk factors for change in QTc interval corrected with the Bazett's formula

\begin{tabular}{|c|c|c|c|c|c|c|c|c|c|}
\hline & & $N$ & Delta QTc & Univariate & & & Multivariat & & \\
\hline & & & & Difference & $95 \% \mathrm{CI}$ & $p$ & Difference & $95 \% \mathrm{CI}$ & $p$ \\
\hline Age & $<65$ year & 39 & 33.0 & Ref & & & & & \\
\hline & $\geq 65$ year & 31 & 32.0 & -1.0 & -16.5 to 14.5 & 0.90 & & & \\
\hline Gender & M & 55 & 32.4 & Ref & & & & & \\
\hline & $\mathrm{F}$ & 15 & 33.1 & 0.7 & -18.1 to 19.5 & 0.94 & & & \\
\hline RR & $<90 \mathrm{bpm}$ & 42 & 22.1 & Ref & & & & & \\
\hline & $\geq 90 \mathrm{bpm}$ & 28 & 48.2 & 26.1 & $11.7-40.5$ & 0.001 & 29.0 & $16.4-41.6$ & $<0.001$ \\
\hline QRS & $<100 \mathrm{~ms}$ & 52 & 34.9 & Ref & & & & & \\
\hline & $\geq 100 \mathrm{~ms}$ & 18 & 26.0 & -8.9 & -26.5 to 8.6 & 0.31 & & & \\
\hline QTc & $<450 \mathrm{~ms}$ & 52 & 38.2 & Ref & & & & & \\
\hline & $\geq 450 \mathrm{~ms}$ & 18 & 16.4 & -21.8 & -38.7 to -5.0 & 0.012 & -26.6 & -41.0 to -12.3 & $<0.001$ \\
\hline eGFR & $\geq 50 \mathrm{ml} / \mathrm{min} / 1.73 \mathrm{~m}^{2}$ & 63 & 29.9 & Ref & & & & & \\
\hline & $<50 \mathrm{ml} / \mathrm{min} / 1.73 \mathrm{~m}^{2}$ & 7 & 57.2 & 27.4 & $2.5-52.2$ & 0.031 & 45.0 & $23.8-66.1$ & $<0.001$ \\
\hline ICU & No & 57 & 30.9 & Ref & & & & & \\
\hline & Yes & 13 & 39.9 & 8.9 & -10.8 to 28.7 & 0.37 & & & \\
\hline
\end{tabular}

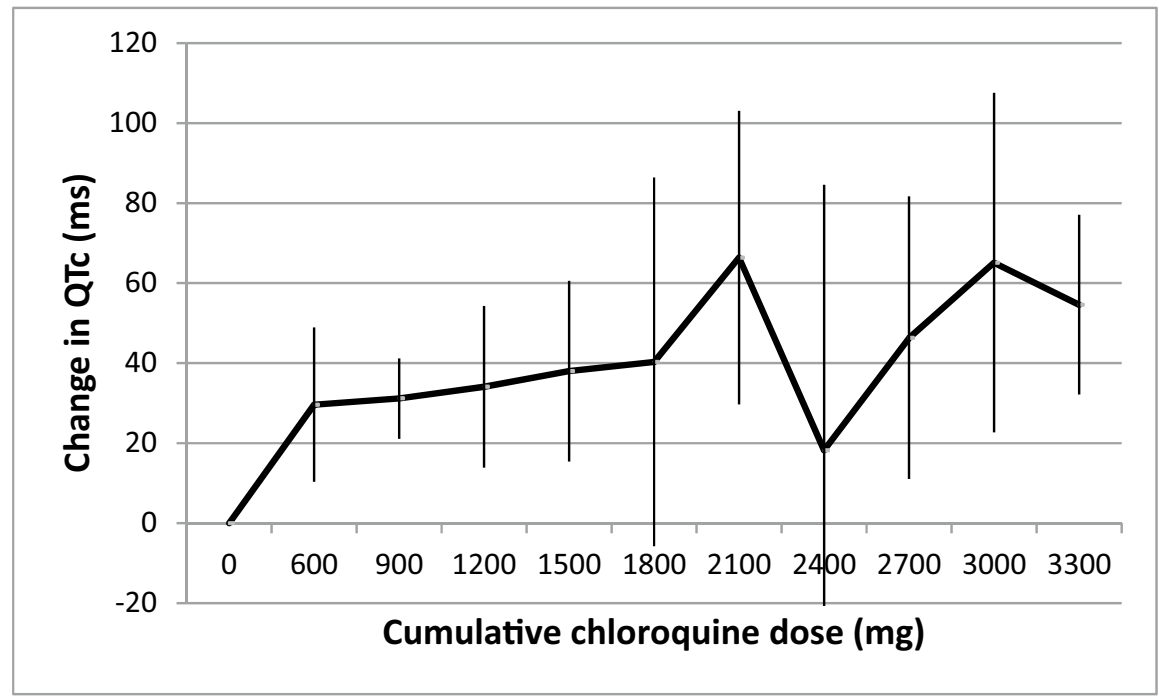

\begin{tabular}{|l|l|l|l|l|l|l|l|l|l|l|l|}
\hline Dose & 0 & 600 & 900 & 1200 & 1500 & 1800 & 2100 & 2400 & 2700 & 3000 & 3300 \\
\hline $\mathrm{N}$ & 70 & 11 & 28 & 25 & 12 & 8 & 6 & 4 & 6 & 4 & 5 \\
\hline
\end{tabular}

Fig. 2 Change in QTc (corrected with the Bazett's formula) versus the cumulative dose of chloroquine at the time of the ECG recording. For all ECGs performed in the study population, the cumulative dose at the time of the ECG is calculated. At each point, all ECGs performed with the cumulative dose on the $x$-axis are analyzed. The $y$-axis represents the average change in QTc interval from base-

patients treated with dexamethasone versus usual care [40]. Adverse events were not reported in this study.

In our study, we corrected the QT interval for the heart rate using both the Bazett's formula and the Fridericia's formula $[22,23]$. The Bazett's formula is the formula most line ECG to the ECGs per cumulative dose. If multiple ECGs are recorded in an individual patient during treatment, more ECGs per patient are included. In the table below the figure, the number of ECGs per cumulative dose is given. Bars are 95\% confidence intervals

frequently used in clinical practice and the cutoff values for QTc prolongation are based on correction with the Bazett's formula. We also used the Fridericia's formula as secondary outcome, because this formula is regarded as a superior formula to correct for heart rate and in predicting mortality 
[41]. Most other studies used the Bazett's formula, while a minority used the Fridericia's formula. The results of our study did not change substantially whether we used the Bazett's or the Fridericia's formula, confirming that the conclusions in our article are independent of the formula used.

Our study has some potential strengths and limitations. A strength is that in 70 of the 106 admitted COVID-19 patients who started with chloroquine treatment $(66 \%)$, an ECG was performed both before and after start of therapy. The guidelines recommended to perform ECGs in patients at increased risk of QTc prolongation; therefore, the incidence found in our study may be an overestimation. However, even if we assume that none of the patients in whom no ECG was performed had a QTc prolongation, still 19 of the 106 patients treated with chloroquine (18\%) would have a prolonged QTc interval. On the other hand, in patients at high risk of QTc prolongation, chloroquine would not have been initiated as previously recommended in our guidelines. This may have resulted in an underestimation of the incidence. In our study, we also analyzed both the QRS and QTc interval to differentiate QTc interval prolongation from QRS widening. A limitation is that we did not include a control group and it might be possible that the QTc prolongation is due to disease progression. However, the QT prolonging effect of chloroquine is established and the QTc prolongation was seen shortly after the start of chloroquine treatment, making an association between chloroquine and QTc prolongation most likely. Another limitation is that due to the observational setting ECGs were performed at different time points. We cannot conclude whether the QTc further prolongs during treatment because in most patients only one ECG was performed during treatment. It is possible that the QTc interval is further prolonged after a 5 day treatment with chloroquine compared to the results in our study because chloroquine has a half-life or around 14 days and will accumulate during treatment. The QT interval was automatically analyzed using the MUSE system. It is debatable whether manual or automated determination of the QT interval is superior [42].

\section{Conclusion}

In our cohort of COVID-19 patients, chloroquine increased the QTc interval with $33 \mathrm{~ms}$ and one in four patients had a QTc interval above $500 \mathrm{~ms}$ or a QTc prolongation of more than $60 \mathrm{~ms}$, potentially causing rhythm disturbances. Since there is no substantial evidence for a beneficial effect of chloroquine and treatment options without cardiovascular toxicity are available, these results discourage its use in COVID-19 patients
Funding This research did not receive any specific grant from funding agencies in the public, commercial, or not-for-profit sectors.

\section{Compliance with Ethical Standards}

Conflict of interest The authors declare that they have no conflict of interest.

Ethical Approval This study was approved by the institutional review board of the Spaarne Gasthuis (Haarlem/Hoofddorp, the Netherlands). All patient data were processed anonymously, according to privacy legislation.

\section{References}

1. Wang, M., Cao, R., Zhang, L., et al. (2020). Remdesivir and chloroquine effectively inhibit the recently emerged novel coronavirus (2019-nCoV) in vitro. Cell Research, 30, 269-271.

2. Yao, X., Ye, F., Zhang, M., et al. (2020). In vitro antiviral activity and projection of optimized dosing design of hydroxychloroquine for the treatment of severe acute respiratory syndrome coronavirus 2 (SARS-CoV-2). Clinical Infectious Diseases. https://doi. org/10.1093/cid/ciaa237.

3. Huang, M., Tang, T., Pang, P., et al. (2020). Treating COVID19 with chloroquine. Journal of Molecular Cell Biology, 12, 322-325.

4. Gao, J., Tian, Z., \& Yang, X. (2020). Breakthrough: Chloroquine phosphate has shown apparent efficacy in treatment of COVID-19 associated pneumonia in clinical studies. Bioscience Trends, 14, $72-73$.

5. Sanders, J. M., Monogue, M. L., Jodlowski, T. Z., \& Cutrell, J. B. (2020). Pharmacologic treatments for coronavirus disease 2019 (COVID-19): A review. JAMA. https://doi.org/10.1001/ jama.2020.6019.

6. Cortegiani, A., Ingoglia, G., Ippolito, M., Giarratano, A., \& Einav, S. (2020). A systematic review on the efficacy and safety of chloroquine for the treatment of COVID-19. Journal of Critical Care, 57, 279-283.

7. Cavalcanti, A. B., Zampieri, F. G., Rosa, R. G., et al. (2020). Hydroxychloroquine with or without azithromycin in mild-tomoderate covid-19. The New England Journal of Medicine. https ://doi.org/10.1056/NEJMoa2019014.

8. Borba, M. G. S., Val, F. F. A., Sampaio, V. S., et al. (2020). Effect of high vs low doses of chloroquine diphosphate as adjunctive therapy for patients hospitalized with severe acute respiratory syndrome coronavirus 2 (SARS-CoV-2) infection: A randomized clinical trial. JAMA Network Open, 3(4), e208857. https://doi. org/10.1001/jamanetworkopen.2020.8857.

9. Jankelson, L., Karam, G., Becker, M. L., Chinitz, L. A., \& Tsai, M. (2020). QT prolongation, torsades de pointes and sudden death with short courses of chloroquine or hydroxychloroquine as used in COVID-19: A systematic review. Heart Rhythm, S15475271(20), 30431-30438.

10. Stichting Werkgroep Antibioticabeleid. (2020). Medicamenteuze behandelopties bij patiënten met COVID-19 (infecties met SARSCoV-2). [Medical treatment options in patients with COVID-19 (infection with SARS-CoV-2)]. Retrieved April 21, 2020, from https://swab.nl/nl/covid-19.

11. Nederlandse Vereniging voor Intensive Care. Handreiking infecties met COVID-19 op de intensive care- nr. 4. [Guide infectionswith COVID-19 on the intensive care nr. 4]. Retrieved April 21, 
2020, from https://nvic.nl/sites/nvic.nl/files/20200316\%20Upd ate\%204\%20-\%20Handreiking\%20infecties_3.pdf.

12. Alhazzani, W., Møller, M. H., Arabi, Y. M., et al. (2020). Surviving Sepsis Campaign: Guidelines on the management of critically ill adults with Coronavirus Disease 2019 (COVID-19). Intensive Care Medicine. https://doi.org/10.1007/s00134-020-06022-5.

13. White, N. J. (2007). Cardiotoxicity of antimalarial drugs. The Lancet Infectious Diseases, 7, 549-558.

14. Smit, C., Peeters, M. Y. M., van den Anker, J. N., \& Knibbe, C. A. J. (2020). Chloroquine for SARS-CoV-2: Implications of its unique pharmacokinetic and safety properties. Clinical Pharmacokinetics. https://doi.org/10.1007/s40262-020-00891-1.

15. Heemskerk, C. P., Pereboom, M., van Stralen, K., et al. (2018). Risk factors for QTc interval prolongation. European Journal of Clinical Pharmacology, 74, 183-191.

16. Tosaki, A. (2020). ArrhythmoGenoPharmacoTherapy. Frontiers in Pharmacology, 11, 616. https://doi.org/10.3389/fphar.2020.00616

17. Lentini, G., Cavalluzzi, M. M., \& Habtemariam, S. (2020). COVID-19, chloroquine repurposing, and cardiac safety concern: Chirality might help. Molecules, 25(8), 1834. https://doi. org/10.3390/molecules25081834.

18. Li, G., Sun, J., Li, Y., Shi, Y., Zhao, J., Zhang, T. Y., \& Zhang, X. (2020). Enantiomers of chloroquine and hydroxychloroquine exhibit different activities against SARS-CoV-2 in vitro, evidencing s-hydroxychloroquine as a potentially superior drug for COVID-19. bioRxiv. https://doi.org/10.1101/2020.05.26.114033.

19. Lakkireddy, D. R., Chung, M. K., Gopinathannair, R., et al. (2020). Guidance for cardiac electrophysiology during the coronavirus (COVID-19) pandemic from the heart rhythm society COVID-19 task force; electrophysiology section of the American College of Cardiology; and the electrocardiography and arrhythmias committee of the council on clinical cardiology, American Heart Association. Heart Rhythm. https://doi.org/10.1016/j.hrthm 2020.03.028.

20. Wu, C. I., Postema, P. G., Arbelo, E., et al. (2020). SARS-CoV-2, COVID-19 and inherited arrhythmia syndromes. Heart Rhythm. https://doi.org/10.1016/j.hrthm.2020.03.024.

21. Woosley, RL and Romero, KA. QT drug list. Retrieved April 15, 2020, from http://www.Crediblemedsorg/.

22. Bazett, H. C. (1920). An analysis of the time-relations of the electrocardiograms. Heart, 7, 353-370.

23. Fridericia, L. S. (1920). Die systolendauer im elektrokardiogramm bei normalen menschen und bei herzkranken. Acta Medica Scandinavica, 53, 469-486.

24. Heemskerk, C. P., Woldman, E., Pereboom, M., et al. (2017). Ciprofloxacin does not prolong the QTc interval: A clinical study in ICU patients and review of the literature. Journal of Pharmacy and Pharmaceutical Sciences, 20, 360-364.

25. Schrijver, E. J., Verstraaten, M., van de Ven, P. M., et al. (2018). Low dose oral haloperidol does not prolong QTc interval in older acutely hospitalised adults: A subanalysis of a randomised doubleblind placebo-controlled study. Journal of Geriatric Cardiology, $15,401-407$.

26. European Medicines Agency. ICH Topic E14 the clinical evaluation of QT/QTc interval prolongation and proarrhythmic potential for non-antiarrhythmic drugs. Retrieved April 23, 2020, from https://www.ema.europa.eu/en/documents/scientific-guideline/ ich-e-14-clinical-evaluation-qt/qts-interval-prolongation-proar rhythmic-potential-non-antiarrhythmic-drugs-step-5_en.pdf.

27. Blom, M. T., Bardai, A., van Munster, B. C., et al. (2011). Differential changes in QTc duration during in-hospital haloperidol use. PLOS ONE, 6, e23728.

28. Vancura, V., Wichterle, D., Ulc, I., et al. (2017). The variability of automated QRS duration measurement. Europace, 19, 636-643.
29. Looareesuwan, S., White, N. J., Chanthavanich, P., et al. (1986). Cardiovascular toxicity and distribution kinetics of intravenous chloroquine. British Journal of Clinical Pharmacology, 22, 31-36.

30. Mzayek, F., Deng, H., Mather, F. J., et al. (2007). Randomized dose-ranging controlled trial of AQ-13, a candidate antimalarial, and chloroquine in healthy volunteers. PLoS Clinical Trials, 2, e6.

31. Cook, J. A., Randinitis, E. J., Bramson, C. R., \& Wesche, D. L. (2006). Lack of a pharmacokinetic interaction between azithromycin and chloroquine. American Journal of Tropical Medicine and Hygiene, 74, 407-412.

32. van den Broek, M. P. H., Möhlmann, J. E., Abeln, B. G. S., et al. (2020). Chloroquine-induced QTc prolongation in COVID-19 patients. Netherlands Heart Journal, 28(7-8), 406-409. https:// doi.org/10.1007/s12471-020-01429-7.

33. Sinkeler, F. S., Berger, F. A., Muntinga, H. J., et al. (2020). The risk of QTc-interval prolongation in COVID-19 patients treated with chloroquine. Netherlands Heart Journal, 28(7-8), 418-423. https://doi.org/10.1007/s12471-020-01462-6.

34. Mercuro, N. J., Yen, C. F., Shim, D. J., et al. (2020). Risk of QT interval prolongation associated with use of hydroxychloroquine with or without concomitant azithromycin among hospitalized patients testing positive for coronavirus disease 2019 (COVID-19). JAMA Cardiol. https://doi.org/10.1001/jamacardio .2020.1834

35. Saleh, M., Gabriels, J., Chang, D., et al. (2020). Effect of chloroquine, hydroxychloroquine, and azithromycin on the corrected QT interval in patients with SARS-CoV-2 infection. Circulation: Arrhythmia and Electrophysiology, 13(6), e008662. https://doi. org/10.1161/CIRCEP.120.008662.

36. Sridhar, A. R., Chatterjee, N. A., Saour, B., et al. (2020). QT interval and arrhythmic safety of hydroxychloroquine monotherapy in coronavirus disease 2019. Heart Rhythm O2, 1(3), 167-172. https ://doi.org/10.1016/j.hroo.2020.06.002.

37. Beigel, J. H., Tomashek, K. M., Dodd, L. E., et al. (2020). Remdesivir for the treatment of covid-19-final report. New England Journal of Medicine. https://doi.org/10.1056/NEJMoa2007764.

38. Wang, Y., Zhang, D., Du, G., et al. (2020). Remdesivir in adults with severe COVID-19: A randomised double-blind, placebocontrolled, multicentre trial. The Lancet, 395(10236), 1569-1578. https://doi.org/10.1016/S0140-6736(20)31022-9.

39. Spinner, C. D., Gottlieb, R. L., Criner, G. J., et al. (2020). Effect of remdesivir vs standard care on clinical status at 11 days in patients with moderate COVID-19: A randomized clinical trial. JAMA, 324(11), 1048-1057. https://doi.org/10.1001/jama.2020.16349.

40. Horby, P., Shen Lim, W., Emberson, J. R., et al. (2020). Dexamethasone in hospitalized patients with covid-19-preliminary report. New England Journal of Medicine. https://doi.org/10.1056/ NEJMoa2021436.

41. Vandenberk, B., Vandael, E., Robyns, T., et al. (2016). Which QT correction formulae to use for QT monitoring? Journal of the American Heart Association, 5(6), e003264. https://doi. org/10.1161/JAHA.116.003264.

42. Postema, P. G., De Jong, J. S., Van der Bilt, I. A., \& Wilde, A. A. (2008). Accurate electrocardiographic assessment of the QT interval: Teach the tangent. Heart Rhythm, 5, 1015-1018.

Publisher's Note Springer Nature remains neutral with regard to jurisdictional claims in published maps and institutional affiliations. 